\title{
Knowledge of Communities about Malaria Control Strategies in Lindi Urban District, Tanzania
}

\author{
Nkulikwa ZA*, Malago JJ and William GW \\ College of Social and Humanities, Sokoine University of Agriculture, Morogor, Tanzania
}

\begin{abstract}
Despite the efforts to minimize malaria infection in Tanzania, its prevalence persists. To what factors is the persistence be attributed? Does people's lack of knowledge, impact negatively on their receptivity of malarial preventive and control strategies? This paper examines knowledge about control strategies of malaria, both curative and preventive, among local native of Lindi Urban district, in Tanzania, with the specific objectives to determine people's knowledge about malaria control strategies. Both qualitative and quantitative data were collected from 356 respondents. Focus group discussion were employed in eliciting qualitative information whereas a structured questionnaire was utilized to collect quantitative data. Both descriptive and inferential statistics were used in the analysis of these data. Descriptive analyses involved computation of frequency and percentages. Inferential measures were determined through Chi-square test. Knowledge of participants was significantly associated $(P<0.05)$ with educational level, location of respondents, marital status and occupation. As such, knowledge about malaria control strategies in the study district was much different between respondents who had different socio-economic factors. However, there was insignificant association $(P>0.05)$ between malarial knowledge, sex, age of respondents and total number of members per household. Conclusively, this paper found that participants had information about malaria preventive strategies; they hardly had knowledge about the cause of malaria, importance of using mosquito nets consistently in protecting themselves from disease, and had no knowledge about how to integrate as well as implement various malaria preventative measures. Additionally, some misconceptions among respondents were discerned regarding cure of malaria, symptoms, and the effectiveness of bed nets.
\end{abstract}

Keywords: Knowledge; Malaria control strategies; Lindi district

\section{Introduction}

Malaria is persistently one of primal causes of morbidity and mortality in tropical and subtropical regions of the earth. It is more debilitating and corrosive to most communities in sub-Saharan Africa; because of its favourable environmental conditions for the development of mosquitoes, which is the vector of the disease, being transmitted by a mosquito called Anopheles. Although the parasite was discovered at least 137 years ago (in 1880), malaria has been a formidable challenge that adversely affect health and well-being of most of Africans WHO and UNICEF (2005) [1]. It has been estimated that one person in Africa dies of malaria in every ten seconds, claiming $91 \%$ of a million lives annually while 300 million people are infected with the disease at any one time and a third of them develop clinical complications (WHO, 2003, 2005, 2008). In 2016, an estimate of 2018 million cases of malaria occurred worldwide. Fifteen countries, which are in sub- Saharan Africa, accounted for $80 \%$ of global deaths caused by this disease [2].

According to malaria was a global challenge in mid- $20^{\text {th }}$ century [3]. Later, in most parts of this earth malaria was eradicated, but, now at least $40 \%$ of humankind, particularly, those who reside in developing countries are at a risk of malaria infection because of the widespread of the disease in tropical and Subtropical regions. Moreover, Kinung argues that given that the epidemiology of malaria relies on environmental factors and weather elements such as temperature, humidity and rainfall. Global warming may cause the resurgence of malaria in population where either it was eliminated or was never experienced before. Additionally, relate epidemiology of malaria to environment that favours the infestation of mosquitoes, and that the spread or its control correlates to demographic characteristics and socio-economic factors like education level, knowledge about malaria and preventive measures [4].
Because of the severity, and difficulty caused by malaria to Africans, the United Nations Children Fund (UNICEF) initiated roll back malaria for Africa in 1998 with the goal to eradicate or ease the intensity of morbidity and mortality attributed to malaria. In addition, in 2000 the United Nations, at its millennium conference in New York, determined that morbidity and mortality vary directly as poverty. Therefore, reduction of morbidity and mortality is decreasing poverty. The above information, the government of Tanzania developed a malaria strategic plan, which is based on curative and preventive measures including supporting strategies in the relentless and continuous fight against the disease. These strategies involve availability and use of mosquito nets, in door residual spraying of dwellings with insecticides, the prophylactic use of antimalarial drugs by pregnant women, diagnostic testing for measuring malaria, and the public use of antimalarial drugs.

Based on Tanzania Demographic and Health Survey and Malaria Indicator Survey (TDHS-MIS), which was conducted between 2015 and 2016, 93\% of population live in environment; which favour breeding of malaria vectors, and hence are at risk. The frequency of malaria occurrence in Tanzania is different from one region to another, with the highest in Western Lake areas and Southern zone areas while it is lowest in Northern, Central, and South West areas of Tanzania.

*Corresponding author: Nkulikwa ZA, College of Social and Humanities, Sokoine University of Agriculture, Morogor, Tanzania, Tel: +255767485156; E-mail: nkulikwa@gmail.com

Received September 12, 2018; Accepted October 03, 2018; Published October 10 2018

Citation: Nkulikwa ZA, Malago JJ, William GW (2018) Knowledge of Communities about Malaria Control Strategies in Lindi Urban District, Tanzania. Health Care Current Reviews 6: 229. doi: 10.4172/2375-4273.1000229

Copyright: () 2018 Nkulikwa ZA, et al. This is an open-access article distributed under the terms of the Creative Commons Attribution License, which permits unrestricted use, distribution, and reproduction in any medium, provided the original author and source are credited. 
The fundamental means in implementing the malaria strategies plan is preventive measures, which are mainly tailored to using durable insecticide nets. Despite these efforts an estimate of 11.5 million malaria cases occur annually in Tanzania with at least $93 \%$ of the population are at risk of being afflicted with by debilitating disease [5]. Moreover, some members of population have been observed mis-using mosquito nets in wailing their latrines, or for fishing [6]. Accordingly, this paper was set out to examine people's knowledge about malaria control strategies.

\section{Methodology}

\section{Study area and design}

This study was conducted in Lindi Urban district. The area is one of the areas where the Tanzanian government implements malaria strategic plan by distributing long-lasting insecticidal nets to schoolchildren [7]. Additionally, according to Tanzania HIV/AIDS and malaria survey report (TDHs-MIS 2012), Lindi region is one of the regions where the greatest number of the households owned treated mosquito nets. Inspite of this fact, according to DTHS-MIS 2012, this area is one of the leading regions in prevalence of malaria in Tanzania. Lindi region comprises six districts namely Lindi Rural, Kilwa, Nachingwea, Liwale, Ruangwa and Lindi urban. It is located in Southern Tanzania between latitude $7^{\circ} 55^{\prime}$ and $10^{\circ} 50^{\prime}$ South of the equator and longitudes $36^{\circ} 51^{\prime}$ to $40^{\circ}$ East between latitudes $7^{\circ} 55^{\prime}$ and $10^{\circ} 50^{\prime}$ South of the Equator and longitudes $36^{\circ} 51^{\prime}$ to $40^{\circ}$ East of the Greenwich Meridian. Lindi Region borders with the Coast region to the North, the Indian Ocean to the East, Mtwara region to the South, Morogoro region to the West and Ruvuma region to the South -West. The climate of Lindi Region is dominantly temperate and humid with a mean temperature of $27^{\circ} \mathrm{C}$. The rainfall is between $780 \mathrm{~mm}$ and 1,200 $\mathrm{mm}$ per year. The region accommodates 781, 306 inhabitants whose mainly activity is farming. The region is famous for producing food like maize, cassava, sorghum, paddy and simsim.

The study on which this paper is based involved 356 respondents and employed a cross-sectional research design. The study utilized one measurement time to describe what existed and that particular time. The cross sectional survey aimed at collecting information from respondents on the knowledge about malaria control and preventive strategies. The tool utilized in the initial identification were purposive, convenient and randomized. The district hospital were purposively selected as a centre for conveniently and randomly collecting information from respondents, who either visited or sought medical attention from hospital. Semi structured questionnaire was employed to collect quantitative data while qualitative data were obtained via semi structured interview and Focus Group Discussion (FGD). FGD was deliberately selected to enhance ecological validity, which is the research setting that would approximate the topic under study. A homogeneous group of eight participants formed the unit of analysis of this paper. This unit for focused group comprised elders, priests and some retired leaders. Researcher with assistance of one of the elders did the recruitment for participants. Each participants was requested for face to face, common times and place was agreed upon. The discussion took 90 minutes.

\section{Data collection procedures}

Data included qualitative and quantitative ones. Qualitative data were collected using group discussions, in which notes were taken and consultation was tape-recorded by the researcher. Regarding quantitative values, data were collected by means of a survey through a structured questionnaire. Using these tools information was gathered about people's knowledge about how one contracts malaria, knowledge about cause of malaria and knowledge about recognition of illness caused by malaria. In addition, the instrument were used to collect information on symptoms, perception about symptoms of malaria and malaria control practice. These involved data of respondents' knowledge about method of prevention, measures used in households; and the preferred methods. These questionnaires were administered in Kiswahili, which is one of the language spoken in the study area.

\section{Data analysis}

Qualitative data obtained through focus group discussions were analysed using content analysis in which the main themes were identified which reflected the intended meaning by respondents, and the contents were classified in accordance with the themes. Analysis of quantitative data was achieved by using Statistical Package for Social Science (SPSS) version 23. Descriptive statistics including frequency distribution, which resulted into percentages where used to describe and summarize the findings whereas, Chi -square test was used for inferential statistics to explore the association between respondents malarial knowledge with their demographic characteristics and socialeconomic factors such as educational level, sex, location, marital status, and age of respondents

\section{Results}

The findings show awareness but least knowledge about malaria and its control strategies. While the results in Table 1 show that $89.6 \%$ of the respondents agreed that they knew the causes of malaria, the findings in Table 2 indicate that at least $91.5 \%$ of 324 respondents in the study area attached the cause of malaria to something else other than what it is. With respect to the results in Table 2, 64.2\% felt that mosquitoes were the cause; $22.5 \%$ of them thought that using untreated mosquito net could expose one to malaria, and $8 \%$ believed that any water that circumscribed a house was responsible for malaria. Furthermore, the results given by analysis of Chi - square test in table; revealed existence of a significant association between respondents' demographic characteristics, socio-economic factors, and awareness cause of malaria at $(\mathrm{P}<0.005)$ (Tables 1 and 2$)$.

\section{Knowledge about identification of malaria illness}

Inadequate level of knowledge on the identification of malaria illness evidenced by the findings in the study area. Table 3 indicates that at least $58.3 \%$ of the respondents based their identification of

\begin{tabular}{|c|c|c|}
\hline Contraction & Frequency & Percent \\
\hline Yes & 319 & 89.6 \\
\hline No & 37 & 10.4 \\
\hline Total & $\mathbf{3 5 6}$ & $\mathbf{1 0 0 . 0}$ \\
\hline
\end{tabular}

Table 1: Knowledge about contraction of malaria $(n=356)$.

\begin{tabular}{|l|c|c|}
\hline \multicolumn{1}{|c|}{ Causes } & Frequency & Percent \\
\hline Mosquito/njenjema & 208 & 64.2 \\
\hline Other Pathogen & 3 & 0.9 \\
\hline I don't know & 6 & 1.9 \\
\hline Using untreated nets & 73 & 22.5 \\
\hline $\begin{array}{l}\text { Not using mosquito nets, house surrounded by } \\
\text { water duddies and not clearing bushes }\end{array}$ & 26 & 8.0 \\
\hline Air & 8 & 2.5 \\
\hline \multicolumn{1}{|c|}{ Total } & $\mathbf{3 2 4}$ & $\mathbf{1 0 0 . 0}$ \\
\hline
\end{tabular}

Table 2: Knowledge about malaria causation $(n=324)$. 
the malaria upon either previous experience with malaria, belief or vomiting and diarrhoea. Only $41.7 \%$ of them realized that they became ill of malaria through laboratory test. However, when they were asked if they knew malaria symptoms $96.6 \%$ of them agreed as denoted by Table 4. This may be a sign that respondents had over-generalized symptoms of other diseases over malaria symptoms. Moreover, in contrast to the respondents claim that they knew symptoms of malaria as findings in Table 4 show, that $64.6 \%$ exclusively said lack of appetite, joint pain, losing weight, sweating and headache were adequate symptoms for malaria. Nevertheless, $34.3 \%$ of them contended that vomiting combined with lack of appetite, joint pain and high temperature were the only symptoms of malaria. Only $(1.2 \%)$ of them knew that they had malaria if they were vomiting (Tables 3 and 4 ).

In addition, the findings, a Chi square test showed significant association between knowledge about identification of malaria infection symptoms and respondents' level with various level of education, location, marital status and occupation. This signalizes that there was a high degree of accurate identification of symptoms of malaria in relation to respondent with various socio-economic factors. Nonetheless, knowledge about identification of malaria infection symptoms was insignificant between respondents with different sex, age and the number of members per household (Table 5). Furthermore, the results in Table 6 demonstrate that respondents had also their own perceptions about some symptoms associated with malaria. During the study, 354 respondents admitted having suffered from malaria often, and reported to have had preconceived knowledge about the symptoms before they knew it was malaria. The findings show that $43.3 \%$ thought it was just a fever; $11.9 \%$ ascribed the symptoms to witchcraft, and only

\begin{tabular}{|c|c|c|}
\hline Malaria identification & Frequency & Percent \\
\hline I knew I had malaria & 121 & 41.7 \\
\hline after laboratory test & 33 & 11.4 \\
\hline I felt the same as with Malaria Previously & 68 & 23.4 \\
\hline I believed i have malaria & 61 & 21.0 \\
\hline vomiting and diarrhoea & 7 & 2.4 \\
\hline Total & $\mathbf{2 9 0}$ & $\mathbf{1 0 0 . 0}$ \\
\hline
\end{tabular}

Table 3: Identification of malaria illness by respondents $(n=290)$.

\begin{tabular}{|c|c|c|}
\hline Variables & Frequency & Percent \\
\hline Yes & 345 & 96.9 \\
\hline No & 11 & 3.1 \\
\hline Total & $\mathbf{3 5 6}$ & $\mathbf{1 0 0 . 0}$ \\
\hline Malaria symptoms & Frequency & Percent \\
\hline $\begin{array}{c}\text { Vomiting } \\
\text { Vomiting, lack of appetite, joint pain and high } \\
\text { temperature }\end{array}$ & 4 & 1.2 \\
\cline { 2 - 3 } $\begin{array}{c}\text { Lack of appetites, joint pain, losing weight, } \\
\text { sweating and headache }\end{array}$ & 119 & 34.3 \\
\hline Total & 224 & 64.6 \\
\hline Table & $\mathbf{3 4 7}$ & $\mathbf{1 0 0 . 0}$ \\
\hline
\end{tabular}

Table 4: Symptoms for Malaria $(n=356)$.

\begin{tabular}{|c|c|c|c|}
\hline Variables & $\mathbf{X}^{\mathbf{2}}$ & $\mathbf{D F}$ & $\mathbf{P}=$ value \\
\hline Education level & $48.650^{\mathrm{a}}$ & 32 & 0.006 \\
\hline Sex & $3.293^{\mathrm{a}}$ & 4 & 0.510 \\
\hline Location & $24.958^{\mathrm{a}}$ & 4 & 0.001 \\
\hline Marital status & $34.977^{\mathrm{a}}$ & 16 & 0.004 \\
\hline Occupation & $50.443^{\mathrm{a}}$ & 28 & 0.006 \\
\hline Age of respondent & $13.610^{\mathrm{a}}$ & 12 & 0.317 \\
\hline Total number per household & $45.220^{\mathrm{a}}$ & 28 & 0.021 \\
\hline
\end{tabular}

Table 5: Association between variables and Malaria identification $(n=354)$.
$33.9 \%$ knew it was malaria through a confirmatory laboratory test. However, the findings in Table 7 indicate that most of them (87.6\%) sought medical attention from hospital.

\section{Knowledge about preventive malaria control strategies}

Despite the fact that $97.8 \%$ of respondents reported that they knew methods to prevent themselves against malaria as indicated in Table 8 , the findings in Table 9 indicate otherwise. These results show that at least $57 \%$ were aware of correct methods like using treated mosquito nets, and just less than a half of the respondents identified wrong preventive strategies. For instance, the findings in Table 9 show that $38.5 \%$ confused general cleanliness with preventive measures. Moreover, as the findings in Table 10 indicate, $60.5 \%$ used mosquito nets where as $35.8 \%$ regarded house cleanliness, removing water puddles and empty containers as their favourite preventive measures. Additionally, the findings in Table 11 indicate that just $56.1 \%$ preferred using mosquito nets to other methods while $45.3 \%$ of them were inclined to using cleanliness. This means that respondents had little knowledge about the effectiveness of some of the preventive measures. These results show some over generalization of containers over containers that are open and consist of water (Tables 11 and 12).

Furthermore, the findings in Table 11 reveal that inspite of the fact that the respondents $56.2 \%$ reported that they preferred using mosquito nets to other methods, it appears that they used mosquito nets for other purposes. In accordance with these results, $77.7 \%$ confirmed that

\begin{tabular}{|c|c|c|}
\hline Perception & Frequency & Percent \\
\hline It was witchcraft & 42 & 11.9 \\
\hline I knew it was Malaria & 120 & 33.9 \\
\hline I know it was just a fever & 154 & 43.5 \\
\hline it was UTI or cholera/ other diseases & 38 & 10.7 \\
\hline Total & $\mathbf{3 5 4}$ & $\mathbf{1 0 0 . 0}$ \\
\hline
\end{tabular}

Table 6: Knowledge of respondents about symptoms of malaria $(n=354)$.

\begin{tabular}{|c|c|c|}
\hline Treatment & Frequency & Percent \\
\hline Using herbal & 26 & 7.3 \\
\hline Sought medical attention at hospital & 312 & 87.9 \\
\hline It was healed without medicine & 12 & 3.4 \\
\hline Drunk a lot of water as cure of malaria & 5 & 1.4 \\
\hline Total & $\mathbf{3 5 5}$ & $\mathbf{1 0 0 . 0}$ \\
\hline
\end{tabular}

Table 7: Seeking treatment for malaria illness.

\begin{tabular}{|c|c|c|}
\hline Variable & Frequency & Percent \\
\hline Yes & 348 & 97.8 \\
\hline No & 8 & 2.2 \\
\hline Total & $\mathbf{3 5 6}$ & $\mathbf{1 0 0 . 0}$ \\
\hline
\end{tabular}

Table 8: Methods for malaria control strategies $(n=356)$.

\begin{tabular}{|c|c|c|}
\hline Preventive measures & Frequency & Percent \\
\hline Using insecticide treated net & 198 & 56.7 \\
\hline Using untreated mosquito nets & 3 & .9 \\
\hline Household cleanness & 51 & 14.6 \\
\hline Clearing the bushes & 62 & 17.8 \\
\hline Removing water puddles & 8 & 2.3 \\
\hline $\begin{array}{c}\text { Removing empty containers around the } \\
\text { household }\end{array}$ & 1 & .3 \\
\hline Using chemical like rungu & 26 & 7.4 \\
\hline Total & $\mathbf{3 4 9}$ & $\mathbf{1 0 0 . 0}$ \\
\hline
\end{tabular}

Table 9: Identification of Ways for prevention of Malaria $(n=349)$. 
mosquito nets were used for activities other than malaria prevention. As the findings in Table 13 indicates, apart from using mosquito nets for malaria preventive measures, bed nets were used in sieving simsim, in fishing activities, in extracting salt from ocean, in gardening, in scaring and snaring birds in their crop fields, and in using them as binder in construction. This signalizes insidious and subtle motive for receiving and accepting mosquito nets distributed by the governments in Lindi Region. Additionally, these findings connote low level of understanding of the importance of the use of mosquito nets in malaria prevention (Tables 12 and 13).

\section{Findings from focus group discussion}

The results from residents' focus group discussion underscores various themes that highlight respondents' perception about malaria preventive measures. These included people's knowledge about preventive methods, medication and the influence of socio- economic factors in controlling malaria. It was learnt that there was misconception about malaria preventive measures. It was noted throughout discussions that participants in the discussions and community members in general believed that malaria could not be prevented using mosquito

\begin{tabular}{|c|c|c|}
\hline Preventive measures & Frequency & Percent \\
\hline Using insecticide treated net & 207 & 59.1 \\
\hline Using normal mosquito nets & 5 & 1.4 \\
\hline Household cleanness & 56 & 16.0 \\
\hline $\begin{array}{c}\text { Clearing the bushes } \\
\text { Removing water logging }\end{array}$ & 67 & 19.1 \\
\hline $\begin{array}{c}\text { Removing empty containers around the } \\
\text { household }\end{array}$ & 5 & 1.4 \\
\hline Using chemical like rungu & 9 & .3 \\
\hline Total & $\mathbf{3 5 0}$ & $\mathbf{1 0 0 . 0}$ \\
\hline
\end{tabular}

Table 10: Preventive measures used by household $(n=350)$.

\begin{tabular}{|c|c|c|}
\hline Preventive measures & Frequency & Percent \\
\hline Using insecticide treated net & 193 & 55.1 \\
\hline Using Normal mosquito & 4 & 1.1 \\
\hline Household cleanness & 82 & 23.4 \\
\hline $\begin{array}{c}\text { Clearing the bushes, removing water logging and } \\
\text { environmental cleanliness }\end{array}$ & 66 & 18.9 \\
\hline Removing water logging & 1 & .3 \\
\hline Using chemical like rungu & 4 & 1.1 \\
\hline Total & $\mathbf{3 5 0}$ & $\mathbf{1 0 0 . 0}$ \\
\hline
\end{tabular}

Table 11: Preference of preventive measures by household $(n=350)$.

\begin{tabular}{|c|c|c|}
\hline Preventive measures & Frequency & Percent \\
\hline Yes & 276 & 77.7 \\
\hline No & 79 & 22.3 \\
\hline Total & 355 & 100.0 \\
\hline
\end{tabular}

Table 12: The other uses of mosquito nets $(n=355)$.

\begin{tabular}{|c|c|c|}
\hline Various usage of mosquito nets & Frequency & Percent \\
\hline Fishing activities & 111 & 40.2 \\
\hline Sieving simsim & 27 & 9.8 \\
\hline Extracting salt from the Indian Ocean & 15 & 5.4 \\
\hline Garden fencing & 71 & 25.7 \\
\hline Scaring birds in crops fields & 34 & 12.3 \\
\hline Binder in construction & 18 & 6.5 \\
\hline Total & $\mathbf{2 7 6}$ & $\mathbf{1 0 0 . 0}$ \\
\hline
\end{tabular}

Table 13: Uses of mosquito nets other than preventive measures $(n=276)$. nets or any other methods that left mosquito infest their household's members. Members of a group of elder group discussants contended: "Truly, based on our experience and what people say in our area, here in Lindi, malaria cannot be prevented by using mosquito nets because no one can sleep the whole night without going to ease one's at night. And toilets are infested with mosquitos." They also agreed as follows: "Not only when you go to toilet, but also people go to bed late, some go to worship at night and others to party at night. And it is impossible to do all these while covering yourself with a net".

It was further noted that there was a pervasive belief among the participants that malaria had no cure and seeking medical attention from hospital would exacerbate the condition. They agreed as follows: "We know there is no medicine for malaria. This is because when you go to hospital a doctor will ask you the medicine you usually use and then the doctor will write for you the medicine you told him. It is clear here that even the doctors do not know the medicine for malaria". That is why they keep trying different types of malaria medication". Moreover, group discussion revealed that people in the study area possibly believed that malaria mainly affect poor people and some educated ones, on the basis that rich people had money to buy residual sprays, which are more potent and effective whereas educated people had knowledge but no means to access such facilities. As regards to this, focus group participants in Lindi agreed: "Educated people, especially who completed form four and form six are as affected by malaria as the poor ones because both groups have no money to buy strong and efficient spraying chemicals that kill each mosquito in a house. But well-off people can afford buying and spraying such chemicals, and so malaria is only for some groups of people".

\section{Discussion}

This study borders on investigation of people's knowledge about malaria control strategies. Knowledge in this study means the capability of an individual to acquire and integrate information and facts, expand and filter them through to gain insight and understanding about malaria, including its control strategies, and use them proficiently. Therefore, in this case, knowledge is a process of actualizing capacity, through experience or education as well as media, to attain capability to make positive decisions about malaria and implement them. Accordingly, the constituent parts of knowledge are information, awareness, insight and wisdom. Following this line of reasoning, the general findings show low level of knowledge, which in addition is compounded by some misconceptions. However, the results indicate relative high awareness in some aspects of knowledge about malaria. Although most of the respondents claimed to know the causes of malaria, they attributed the causes to mosquitoes, other pathogens, using untreated nets and houses encircled by puddles of water. They had no understanding of causation of malaria or they confused between transmission and causality. These findings corroborate the results found in Kenya where respondents showed similar results (Rosana, 2011); such as attributing the cause of malaria to witchcraft, demons, mosquitoes and puddles of water. The misunderstanding that malaria is caused by other factors other than mosquito vector could be an obstacle to knowledge and effectiveness of control strategies of the disease. Those who lack knowledge about the causation of the disease through mosquito vector are likely to feel so overwhelmed by causes of malaria that they cannot take any preventive measures or adopt wrong methods. Presumably, they tend to protect themselves when using mosquito nets against the nuisance of stinging of mosquitos rather than against malaria because of the perception that mosquitoes are not the only cause. 
Furthermore, low level of knowledge is not unique to this paper; other researchers in Tanzania, Nigeria and Zimbabwe observed low knowledge and awareness of causes of malaria and its prevention in communities [8-10]. Consequently, communities do not understand and distinguish causes and transmission of malaria, including the environment in which mosquito thrive. This could help members of the communities to build their own capacities and take initiatives to combat the disease. However, other studies show high level of awareness of knowledge about malaria in Tanzania, Iran and Cameroon, in spite of the steadiness of morbidity due to the disease [8-12]. These researchers advanced the argument for morbidity on the following reasons: unstrained availability of antimalarial medicines to the public; delayed health seeking tendencies; and prescription of antimalarial medication that are symptoms dependent. Although these findings appear to contradict the results of this study, they confirm, by the virtue of the definition of knowledge of this paper, that there was least knowledge in communities about malaria causes. If these people had such knowledge, they would have developed early seeking behaviour: they would have established legal and judicious use of antimalarial drugs, and confirmatory laboratory tests would have been a requirement before any further medical attention. Additionally, a high level of awareness of malaria is not adequate to enable people to employ malaria control strategies. Consequently, it would be plausible, with respect to the results in this paper, to develop a mechanism for acquiring knowledge about malaria that should be established from the grassroots.

As regards knowledge about the identification of malaria illness, it can be noted that there was a reliance on symptoms to identify illness by the respondents. Early and correct detection of malaria is a reliable determinant for early health seeking behaviour; otherwise it may lead to unwittingly delay and, accordingly, perpetual morbidity and mortality. Findings in this study showed a few respondents used confirmatory laboratory tests as a basis to recognize the illness. This can be attributed to low level of education among the respondents because it was significantly associated with identification of the illness as the results in Table 5 indicate. These findings are in line with who also found that knowledge of malaria was strongly associated with the level of formal knowledge. Those who had got education at primary level, secondary level, and some post-secondary level could gain some understanding of the importance of the laboratory tests in classes they would attend, through reading books and malaria campaigns through radio, television, newspapers and scientific magazines. Furthermore, education is a force which enables one to acquire knowledge and integrate it, compare and contrast between similar symptoms, classify them, and then make proper decision on how to deal with illness. Education is a powerful force that advances communities and can enable people to plan, make decisions, and implement them. In this regard, Hanafi-Bojd [12] found that the higher the level of education of respondents the higher the degree of willingness was in participating and engaging in malaria control programmes $[12,13]$.

Despite the fact that the respondents showed high level of awareness of malaria symptoms such as vomiting, lack of appetite, joint pain and rise in temperature including headache, they had some misconceptions about some of these symptoms. For example, some attributed the initial symptoms to witchcraft or fever. This can be explained by the fact that lay men/women tend to confuse coincidence with causality and have propensity for inexperience. In addition, people with no formal education may make judgement based on events rather than inter-relationship processes. Studies from Kenya and Tanzania like Rosana, Sumari $[14,15]$ found that some respondents associated transmissions of malaria with eating unclean food, being in contact with malaria patients, and going to toilets barefooted. Nevertheless, most respondents would seek medical attention from local health centres once they realized that it was malaria. Nonetheless, this contradicts the information obtained through focus group discussions that some people believed that there was no cure for malaria and then it was no use to go to hospital. This contradiction can be explained by the fact that some respondents were somewhat affected by halo effect that the researcher was a secret agent whose motive was to identify those who misused the provided mosquito nets. The researcher discerned this when in one focus group discussion the discussants said in advetently that the researcher was a government agent [16].

Interviewed participants indicated a high level of conglomerate of information (to have information that cannot be used meaningfully) of preventive measures like using insecticide treated nets, clearing bushes and draining water puddles and sleeping under bed nets as the prevalent method of malaria control strategies. While Amusan found, in Nigeria, that the majority of respondents owned and used mosquito nets appropriately, this study noted misuse of the distributed nets. More than three-quarters (77.7\%) of the respondents said that bed nets were being used for other activities such as fishing and to extracting salt from the nearby Indian Ocean in the study area. This could explain the difference between the results of these two studies. While a study, which was conducted in Nigeria, had $94.6 \%$ of respondents having formal education, only $39.7 \%$ of participants in this study had gone to school. As Understanding Society (2014) asserts that education is a reliable predictor of health outcomes in comparison with marital status, age, sex and occupation. It follows then from this paper, that respondents could not structure information of preventive measures and put it into meaningful use.

Moreover, in this study, misconceptions were observed about the use of mosquito nets in preventing malaria. This indicates a huge knowledge gap between malaria prevention programmes mobilizers and consumers. While government and NGOs are striving to distribute bed nets through campaigns in order to control malaria (as reported by TDHS-MIS (2016), the programme bearers believe and act somewhat otherwise. This tendency may emanate from the fact people become ill of malaria even when they use bed nets. Since people might stay in their living rooms talking to each other and since some wake up early in the morning to go to mosques or farming, then there is high probability that they can contract malaria in this way. If these conditions occurs to many of them, then, due to least knowledge about malaria which is compounded by low level of education, they can overgeneralize that mosquito nets are ineffective. Consequently, it is plausible to educate or train people in their communities to employ multi-preventive measures in controlling malaria. A study by Zangpo found similar results. In addition, the respondents perceived malaria as a disease of the poor and some so called educated people. They believed that rich people could control malaria easily. This implies that attitude of residents in this region towards malaria strategies should be investigated. Such indicators of negative attitudes and misconceptions about the relation of malaria and some categories of members of the community may lead to disregard training and seminars about malaria, given that people have negative perception about preventing malaria by community. Ultimately, this may have a debilitating effect to these communities, if unchecked [17] 


\section{Study Implications and Conclusions}

The results from this study have some contribution to understanding people's knowledge about malaria in Lindi district. This implies that any programme to succeed in controlling malaria must take on board the knowledge and perceptions of people who are the recipients of the preventive measures. Furthermore, this study highlights that one aspect of knowledge like awareness or information is not enough and sufficient to bring about drastic change in combating malaria. For progress to be made, all aspects of knowledge which can be achieved through education and training are to be considered. Among these are raising awareness of the disease and its associated preventive measures, deepening the understanding of the coherent dynamic relation of awareness and wisdom (which is application of skills required according to exigencies of time) and keeping on refining the acquired conception or information through the mechanisms founded within localities $[18,19]$.

Moreover, this study sheds light on the need to create local mechanism that can ensure proper use of mosquito nets provided to members of communities. This must be accompanied with creating a sense of ownership and pride, which can be attained by introduction of some meagre contribution or attached price to each mosquito net given. Above all, this study suggests that the level of acceptance, attitude and perceptions about malaria strategies introduced to any community must be assessed in advance. The communities should be empowered by local government to hold local training on multivariate malaria preventive measures. This can be achieved using local schoolteachers and some volunteers from the same communities. Conclusively, based on the findings of the study, the respondents were familiar with preventive strategies but had little knowledge about malaria causes, how to utilize the preventive measures, and the importance of using bed nets to prevent malaria infection.

\section{References}

1. Sharma SK, Tyagi PK, Padhan K, Upadhyay AK, Haque MA, et al. (2007) Epidemiology of malaria transmission in forest and plain ecotype villages in Sundargarh District, Orissa, India. Trans R Soc Trop Med Hyg 100: 917-925.

2. WHO (2017) World Malaria Report. Geneva.

3. Adegun, Adegboyega, Awosusi (2011) Knowledge and the preventive strategies of malaria among migrant farmers in ado-ekiti local government area of ekiti state, Nigeria. Am J Sci and Ind Res 2: 883-889.

4. Lucas AO, Gilles HM (2003) Short textbook of public health medicine for the Tropics.
5. Makundi EA, Malebo HM, Mhame P, Kitua AY, Warsame M (2006) 'Role of traditional healers in the management of severe malaria among children below five years of age: The Case of Kilosa and Handeni Districts, Tanzania'. Malar J 5: 1-9.

6. Mboera LE, Makundi EA, Kitua AY (2007) Uncertainty in malaria control in Tanzania: Crossroads and challenges for future interventions. Am J Trop Med Hyg 77: 112-118.

7. Tanzania demographic and health survey and malaria indicator survey (TDHSMIS) 2015-16.

8. Mayala BK, Fahey CA, Wei D, Zinga MM (2015) Knowledge, perception and practices about malaria, cli-mate change, livelihoods and food security among rural communities of central Tanzania. Infect. Dis. Poverty 4: 21.

9. Sigh R, Musa J, Singh S, Ebere UV (2014) Knowledge, attitude and practices on malaria among the rural communities in Aliero, northern Nigeria. J Fam Med Prim Care 3: 39-44.

10. Midz N, Mtapuri-Zinyowera S, Mapingure MP, Paul NH (2011) Knowledge attitudes and practices of grade three primary schoolchildren in relation to schistosomiasis, soil transmitted helminthiasis and malaria in Zimbabwe. BMC infect Dis 11: 169 .

11. Mazigo HD, Obasy E, Mauka W, Manyiri E, Zinga M, et al. (2010) Knowledge, attitudes, and practices about malaria and its control in rural northwest Tanzania. Malar Res Treat 2010: 1-9.

12. Hanafi-Bojd AA, Vatandoost $H$, Oshaghi MA, Eshraghian MR, Haghdoost AA, et al. (2011) Knowledge, attitudes and practices regarding malaria control in an endemic area of Southern Iran. Southeast Asian J Trop Med Public Health 42: 491-501.

13. Kimbi HK, Keka FC, Nyabeyeu HN, Ajeagah HU, Tonga CF, et al. (2012) An update of asymptomatic falciparum malaria in school children in Muea, Southwest Cameroon. J Bacteriol Parasitol 3: 154.

14. Rosana Masese (2011) Socio- cultural factors and health seeking behaviour: A case study of malaria in Kisii district- Kenya.

15. Sumari D, Grimberg BT, Blankenship DA, Mugasa J, Mugittu K, et al (2016) Application of magnetic cytosmear for the estimation of Plasmodium falciparum gametocyte density and detection of asexual stages in asymptomatic children. Malar J 15: 113

16. Mmbando BP, Vestergaard LS, Kitua AY, Lemnge MM, Theander TG, et al. (2010) A progressive declining in the burden of malaria in north-eastern Tanzania. Malar J 9: 216.

17. Okiro EA, Hay SI, Gikandi PW, Sharif SK, Noor AM, et al. (2007) The decline in paediatric malaria admissions on the coast of Kenya. Malar J 6: 151.

18. Tanzania HIVIAIDS and Malaria Indicator Survey 2011-12.

19. Amusan VO, Umar YA, Vantsaw PA (2017) Knowledge, attitudes and practices on malaria prevention and control among private security guards within kaduna metropolis, kaduna State-Nigeria. Sci J Public Health 5: 240-245. 